\title{
Earthquake response of heavily damaged historical masonry mosques after restoration
}

\author{
Ahmet Can Altunışık and Ali Fuat Genç \\ Department of Civil Engineering, Karadeniz Technical University, Trabzon, 61080, Turkey \\ Correspondence to: Ahmet Can Altunışık (ahmetcan8284@hotmail.com)
}

Received: 11 April 2017 - Discussion started: 20 April 2017

Revised: 26 August 2017 - Accepted: 7 September 2017 - Published: 20 October 2017

\begin{abstract}
Restoration works have been accelerated substantially in Turkey in the last decade. Many historical buildings, mosques, minaret, bridges, towers and structures have been restored. With these restorations an important issue arises, namely how restoration work affects the structure. For this reason, we aimed to investigate the restoration effect on the earthquake response of a historical masonry mosque considering the openings on the masonry dome. For this purpose, we used the Hüsrev Pasha Mosque, which is located in the Ortakapi district in the old city of Van, Turkey. The region of Van is in an active seismic zone; therefore, earthquake analyses were performed in this study. Firstly a finite element model of the mosque was constructed considering the restoration drawings and 16 window openings on the dome. Then model was constructed with eight window openings. Structural analyses were performed under dead load and earthquake load, and the mode superposition method was used in analyses. Maximum displacements, maximumminimum principal stresses and shear stresses are given with contours diagrams. The results are analyzed according to Turkish Earthquake Code (TEC, 2007) and compared between 8 and 16 window openings cases. The results show that reduction of the window openings affected the structural behavior of the mosque positively.
\end{abstract}

\section{Introduction}

Masonry is the oldest and a common construction technique in the world. It is a sustainable, easy and economical construction method, but its share of the construction market has decreased in recent decades (Salmanpour et al., 2015). This is due to the availability of new construction techniques. Even

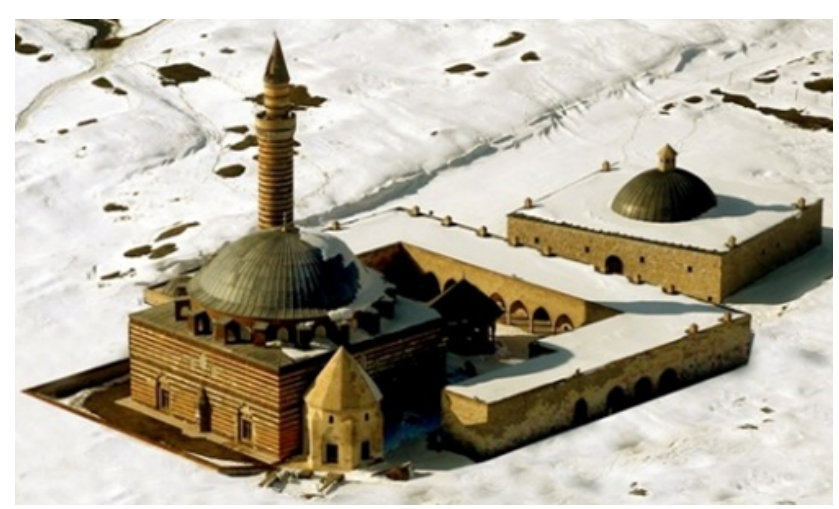

Figure 1. Undamaged view of the Hüsrev Pasha Mosque and social complex.

though many constructions techniques have been developed and used in the last century, almost all historical structures all over the world made up of unreinforced masonry (Chisari et al., 2015).

In the course of time masonry structures have been affected heavily by natural and man-made disasters. However, one of the most destructive factors is earthquakes. Earthquakes create horizontal load and cause tensile stress in masonry structures, which have very low tensile strength. Therefore, it is of vital importance to investigate the earthquake behavior of the masonry structures.

Earthquake behavior of masonry structures are related to some parameters such as material properties, shape of structure, support and load situations. In addition to these, another important factor exists in masonry structures, namely the openings in masonry walls. It is commonly accepted that the presence of openings reduces the lateral stiffness and 

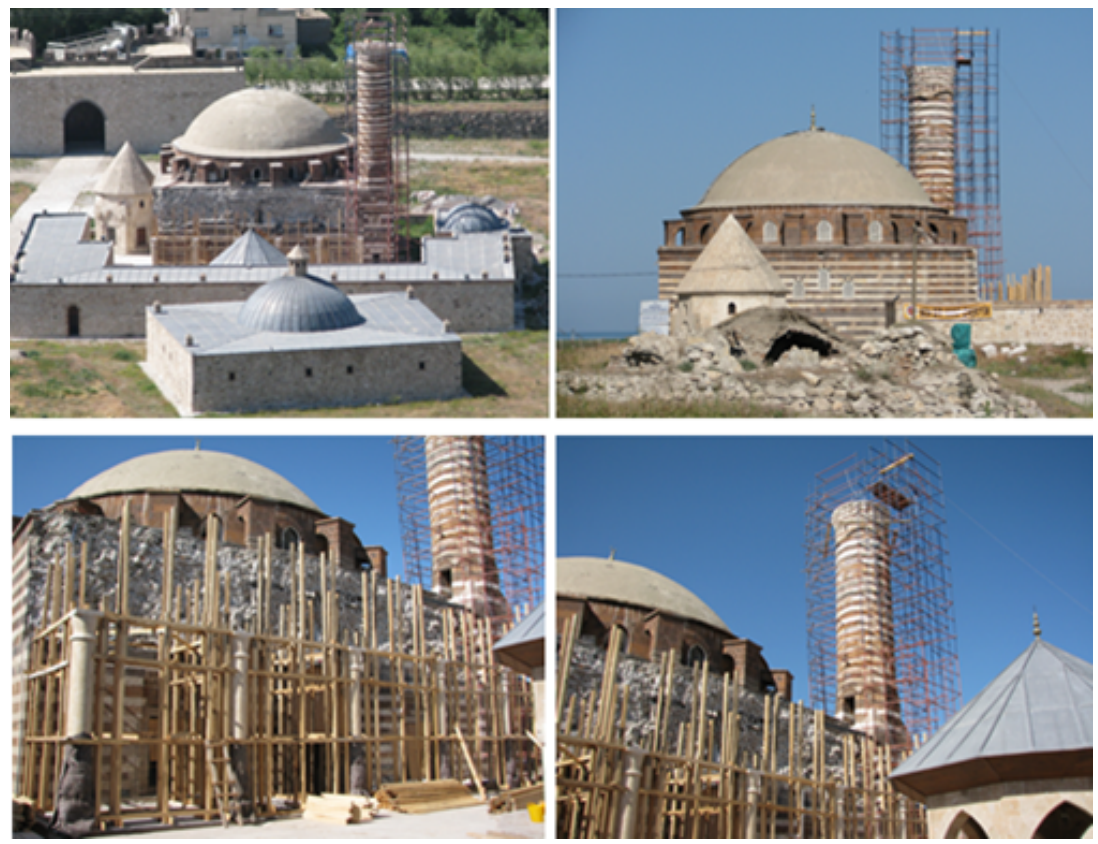

Figure 2. Damaged views of the Hüsrev Pasha Mosque.
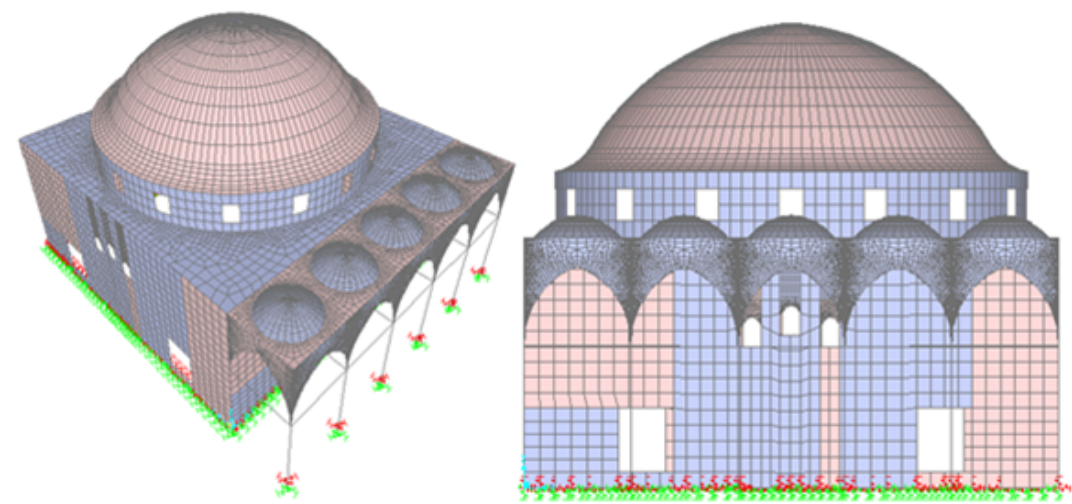

Figure 3. Finite element model of the mosque with 16 window openings.

strength of the infilled system (Chen and Liu, 2015). However, there is still debate over how the openings are located in the systems and how openings affect the earthquake behavior of the system. There have been few studies performed by researchers about this subject. In the Turkish Earthquake Code (TEC, 2007) there is some information about openings in masonry, but it is very limited.

There are many studies in the literature about historical masonry structures. Almost every aspect of the subject has been examined experimentally and numerically. Historical masonry arch bridges (Milani and Lourenço, 2012; Altunisik et al., 2015), towers (Peña et al., 2010), minarets and mosques (Seker et al., 2014), churches (Brandonisio et al., 2013), buildings and walls (Shariq et al., 2008; Lin et al., 2012; Parisi et al., 2013), and chimneys (Minghini et al.,
2014) have all been investigated by different authors. Very rigid structures such as castles, fortresses and bastions have been investigated in terms of static and dynamic structural behavior (Betti et al., 2011; Tiberti et al., 2016).

Mosques, which have a beautiful appearance and high religious value, are very important for Muslims. Many mosques have been built in Muslims area, and most of them were built with masonry techniques. There are many masonry mosques in Turkey, and most of these mosques are in seismic zones. The presence of earthquakes in Turkey has caused damage to and at times the destruction of masonry mosques. Additionally, the Hüsrev Pasha Mosque, which was located in an active seismic zone, was damaged by some seismic events. In the restoration of the Hüsrev Pasha Mosque, the reduction of window openings on the dome to improve the structural 
Table 1. Material properties of the Hüsrev Pasha Mosque.

\begin{tabular}{llrrr}
\hline & Carrier system components & \multicolumn{3}{c}{ Material properties } \\
\cline { 3 - 5 } & & Modulus of elasticity $\left(\mathrm{N} / \mathrm{m}^{2}\right)$ & Poisson ratio $(-)$ & Density $\left(\mathrm{kg} \mathrm{m}^{-3}\right)$ \\
\hline Prayer location & Cut stones & $1.60 \times 10^{9}$ & 0.200 & 2000 \\
& Coarse stone (considering the mortar) & $4.50 \times 10^{8}$ & 0.200 & 2400 \\
& Brick & $1.20 \times 10^{9}$ & 0.200 & 2400 \\
\hline Outer part of prayer location & Cut stones & $1.60 \times 10^{9}$ & 0.200 & 2000 \\
& Marble & $3.54 \times 10^{10}$ & 0.316 & 2690 \\
& Stretcher & $2.00 \times 10^{11}$ & 0.300 & 7850 \\
\hline
\end{tabular}
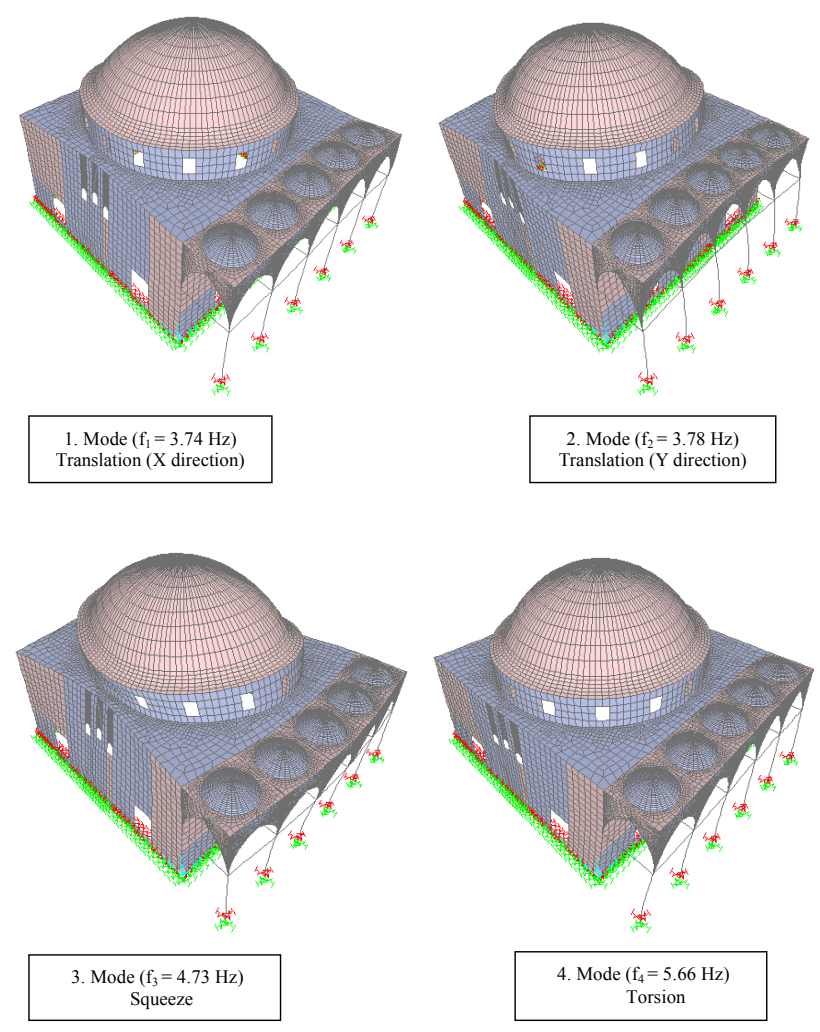

Figure 4. First four mode shapes and frequencies.

performance has been implemented. Therefore, the investigation of this case is necessary. For this purpose, the restoration effect also reduction of window openings effect on the earthquake response of masonry mosques are investigated in this paper.

\section{Hüsrev Pasha Mosque}

The Hüsrev Pasha Mosque is located in the Ortakapı district in the old city of Van, Turkey. The mosque was built by Koca Hüsrev Mehmed Pasha, who was the governor of Van and vizier of Suleiman the Magnificent. The mosque was con-

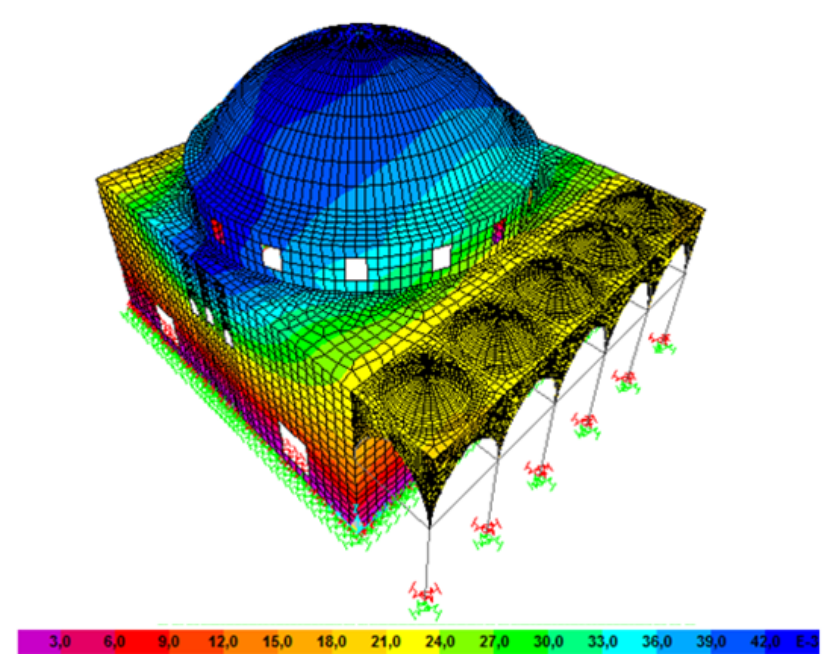

Figure 5. Maximum displacements contour diagram of the mosque with 16 window openings under dead load and earthquake load in the $x$ direction $(\mathrm{G}+\mathrm{EX})$.

structed by the famous Turkish architect Mimar Sinan between 1567 and 1568.

The mosque has one big dome and five small domes. The big and the small domes covered the central prayer area ("nave") and porch respectively. The mean prayer area has a $15.00 \times 15.20 \mathrm{~m}$ geometric shape, and the walls which surround this area are $2 \mathrm{~m}$ thick. The walls consist of cut stone and rough stones, and transition elements and domes consist of bricks material. Limestone was used for bonding in the walls. The mosque has a minaret which has a square shape base and cylindrical body. Originally, there were china ornaments on the walls up to a $2 \mathrm{~m}$ height and pencil art on the dome in the mosque, but most this art and these decorations no longer exist today. Exterior parts of the mosque have colorful stonemasonry, namely red-white stones up to underside of windows and black-white stones on the rest of the walls with red ribbons. There is an historical inscription above the mosque's door.

The mosque is located in an active seismic region classified as a second degree earthquake zone in the seismic zoning map which was published by the Ministry of Public Works 


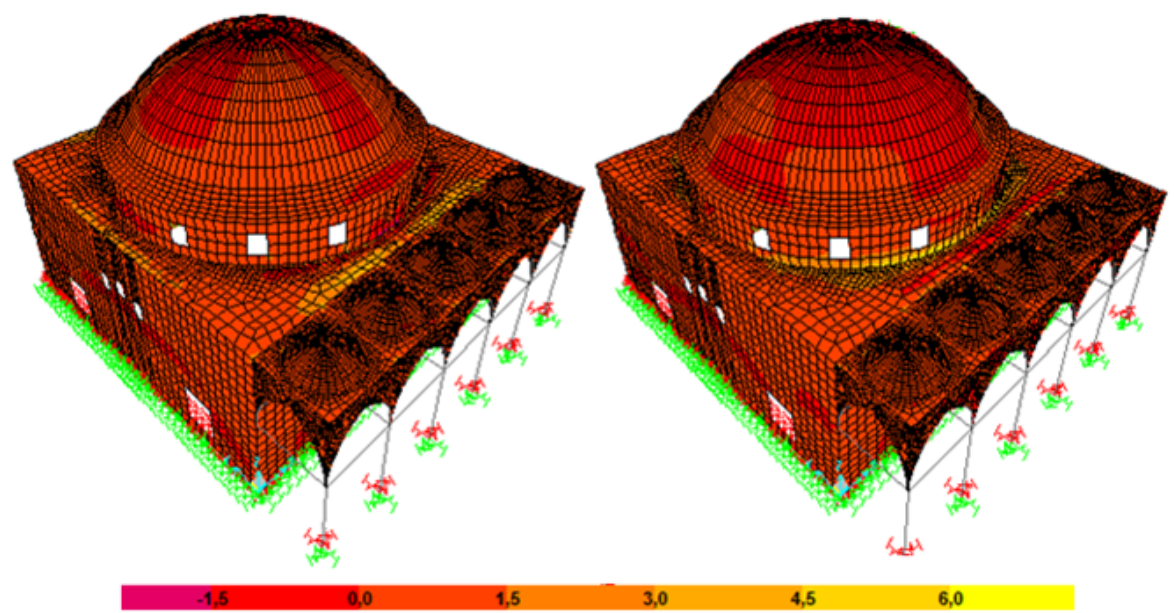

Figure 6. Maximum tensile stresses contour diagram for the outer and inner surfaces of the mosque with 16 window openings under dead load and earthquake load $(\mathrm{G}+\mathrm{EX})$.

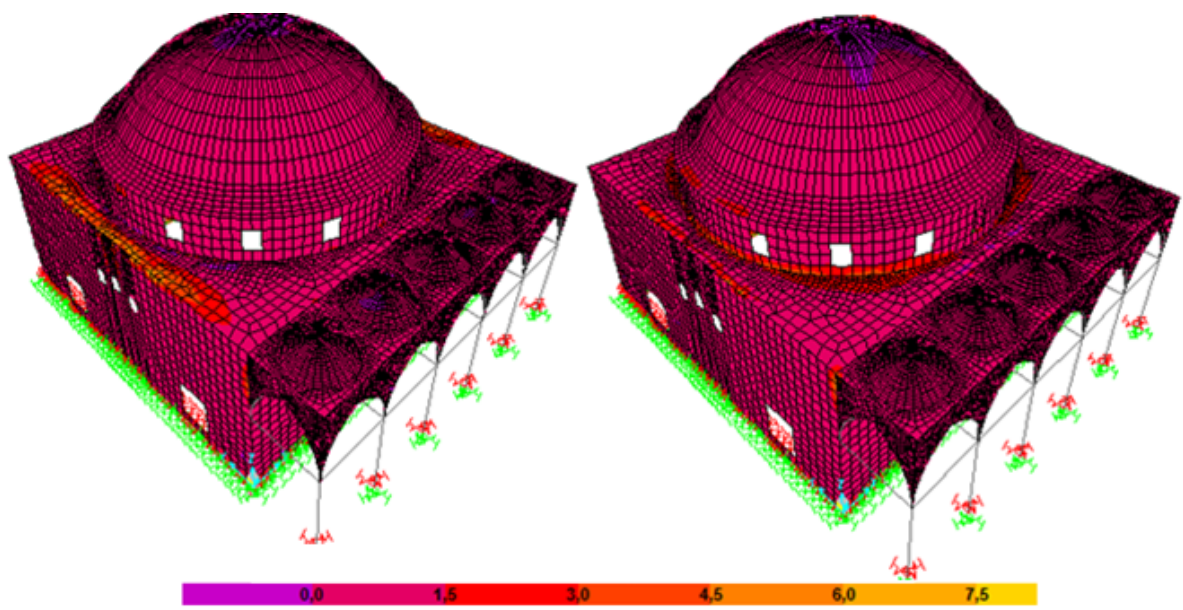

Figure 7. Maximum compression stresses contour diagram for the outer and inner surfaces of the mosque with 16 window openings under dead load and earthquake load $(\mathrm{G}+\mathrm{EX})$.
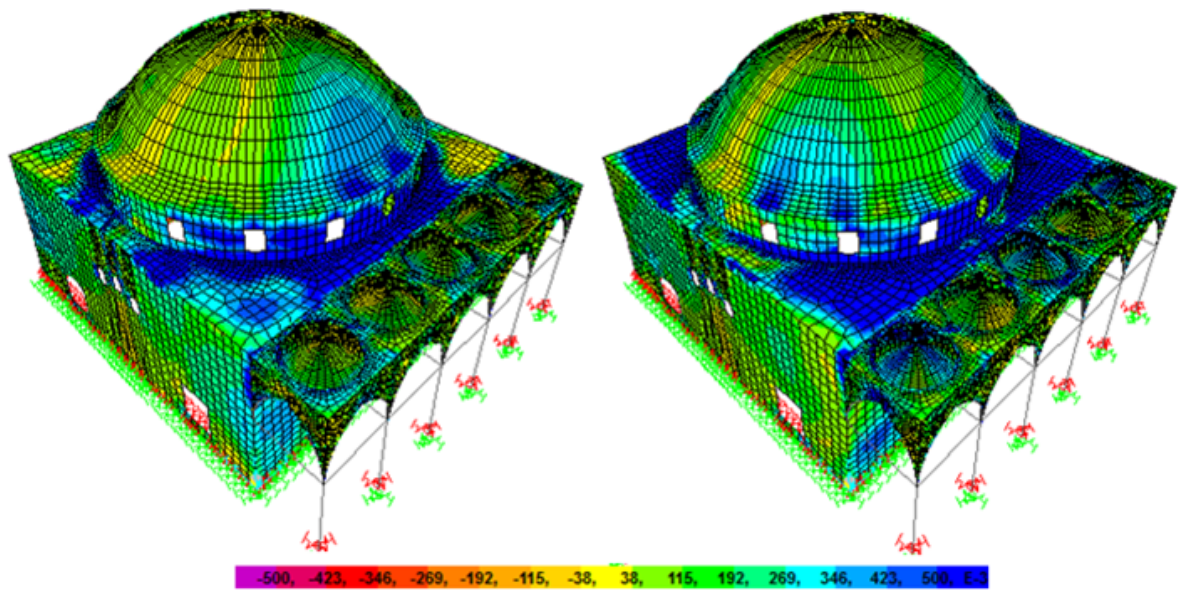

Figure 8. Maximum shear stresses contour diagram for the outer and inner surfaces of the mosque with 16 window openings under dead load and earthquake load $(\mathrm{G}+\mathrm{EX})$. 


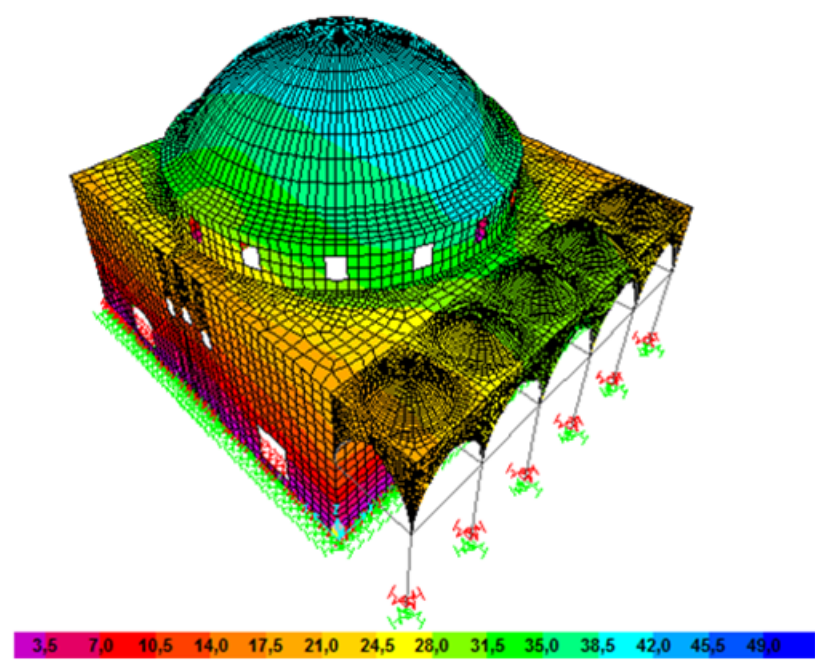

Figure 9. Maximum displacements contour diagram of the mosque with 16 window openings under dead load and earthquake load in the $y$ direction $(\mathrm{G}+\mathrm{EY})$.

and Settlement of Turkey in 1996. Because of this characteristic, the mosque has been damaged severely by earthquakes. The mosque and social complex which had stood for centuries were damaged by the 1839 earthquake and fire. After this unfortunate event the complex was restored. During World War I the complex and mosque were vandalized heavily. In addition to these events, the complex and mosque were ruined by the 2011 Van earthquakes. The minaret and last prayer area were heavily damaged in these earthquakes. Today the prayer area and shrine are structurally sound, but the rest of the complex is highly damaged or has been destroyed. For this reason the mosque was closed for praying, and the aim of the restoration project is to open the mosque for praying. Undamaged views of the mosque are given in Fig. 1.

Today there are some influences which detrimentally affect the structural performance of the mosque. These influences are structural cracks, material deformations, destroyed parts of the carrier system, and environmental issues (e.g., algae and humidity). Some views of these influences and damaged views of the mosque are shown in Fig. 2.

\section{Structural analysis of the mosque}

Finite element analyses were performed to investigate the restoration effect on the earthquake behavior of the mosque, considering different opening ratios on the dome. The model was designed using restoration drawings considering 8 and 16 openings on the dome. Finite element models of the mosque were created with SAP2000 software (SAP2000, 2015). The earthquake ground motions have three components, in the $x, y$ and $z$ directions, which were analyzed to better comprehend the restoration effect with different openings on the dome, and the results were compared to evaluate the structural response of the mosque. After analyses of maximum displacements, maximum-minimum principal stresses and shear stresses were obtained, and the results are given with contour diagrams. Structural analyses of the mosque with 16 and 8 window openings are listed below:

- Modal analysis of the mosque.

- Dead load and earthquake load ( $x, y, z$ direction).

Finite element models of the mosque were designed using frame, area and 3-D solid elements in the SAP2000 program. The bar, area and 3-D solid elements have 2, 4 and 12 nodes respectively, and each node has three degrees of freedom.

Linear elastic methods cannot give exact solutions in the structural analyses of historical masonry structures which are built using bricks and stones. Despite that, nonlinear analyses can give exact results if the material properties of masonry are defined in the analyses correctly. However, if the analyzed structures are very large and complex, there could be some problems in the iterations in nonlinear analyses. Additionally, defining the material properties of masonry structures is fairly difficult because of their non-homogeneity. For these reasons all analyses were performed using a linear elastic method. Material properties which were used in the analyses are given with Table 1.

Finite element analyses results, displacement, section effect and stress values were controlled by considering the allowed values in the 2007 Turkish Earthquake Code (TEC, 2007; chap. 5.3, Pressure Safety Stresses of Walls in which Free Pressure Strength is Unknown). Safety stresses for the Hüsrev Pasha Mosque are given in Table 2.

The mode superposition method was used in earthquake analyses, and the elastic behavior of the mosque under vertical and earthquake loads was obtained with using the full square consolidation method. The spectral acceleration coefficient was taken as $S(T)=2.5$, and the effective earthquake coefficient was chosen as $A_{o}=0.3$ for related the region which is in the second seismic zone. In masonry structures, when the tension stresses surpasses the tension strength of the material, cracks and weakening occur. This situation is taken into consideration in the analyses by using the earthquake load reduction coefficient $\left(R_{a}\right)$ in each period. No reduction was performed in this study $\left(R_{a}=1\right)$, but safety stresses are increased 3 times.

The Hüsrev Pasha Mosque was not built considering any building code; it was built using experience. There are some rules about openings for masonry in the Turkish Earthquake Code (2007). When the mosque is assessed and these rules are considered, there is no discrepancy with the code. Some of the rules that exist in the code regarding openings for masonry related to this study are given below (TEC, 2007):

- The plan length of the solid masonry wall which is between the corner of a building and the nearest window or door opening shall not be less than $1.50 \mathrm{~m}$ for the 


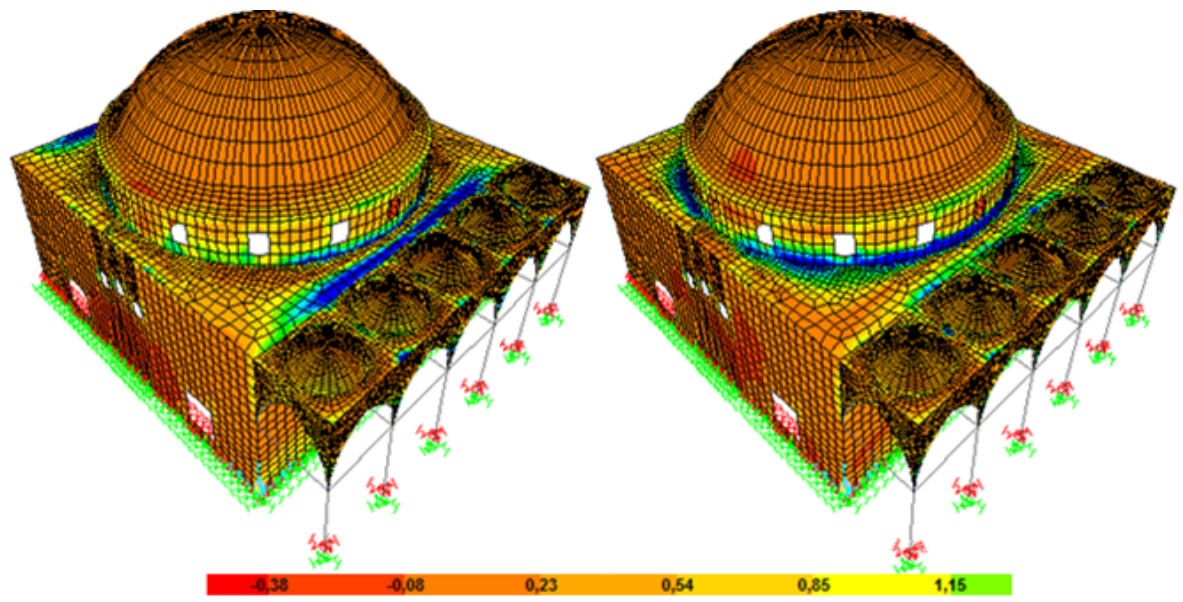

Figure 10. Maximum tensile stresses contour diagram for the outer and inner surfaces of the mosque with 16 window openings under dead load and earthquake load $(\mathrm{G}+\mathrm{EY})$.

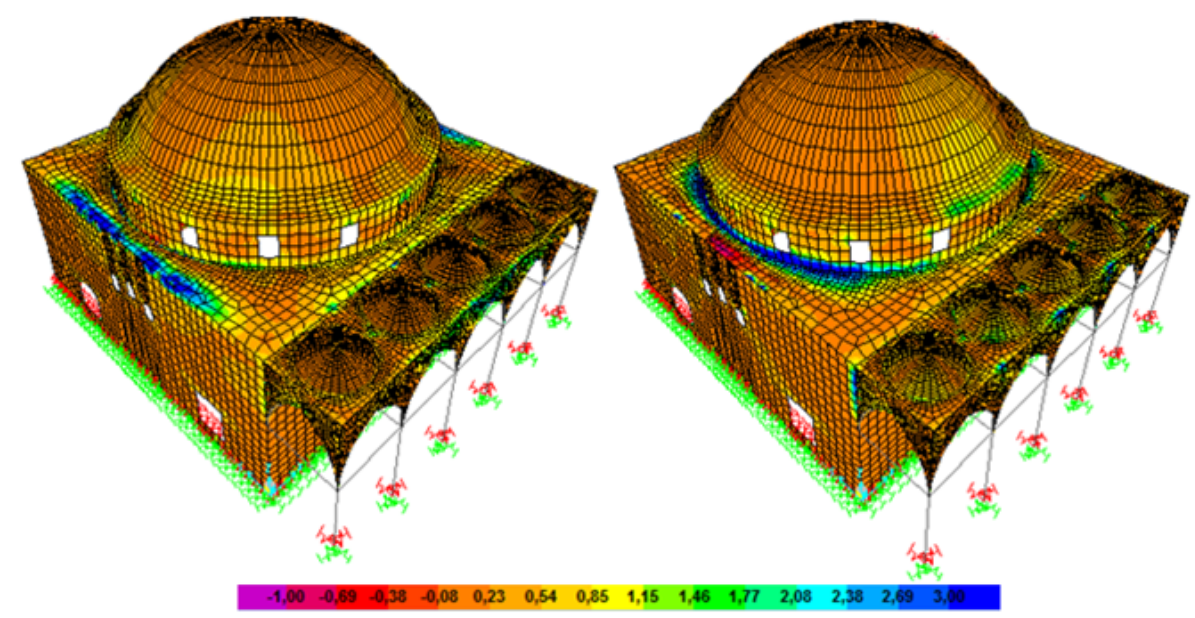

Figure 11. Maximum compression stresses contour diagram for the outer and inner surfaces of the mosque with 16 window openings under dead load and earthquake load $(\mathrm{G}+\mathrm{EY})$.

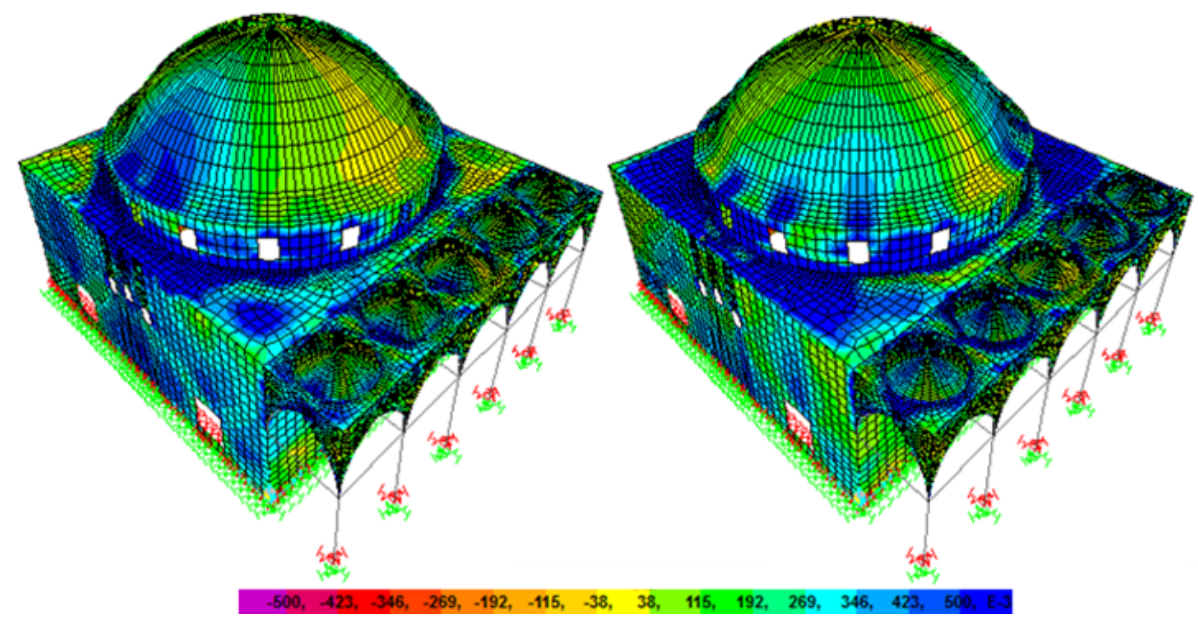

Figure 12. Maximum shear stresses contour diagram for the outer and inner surfaces of the mosque with 16 window openings under dead load and earthquake load $(\mathrm{G}+\mathrm{EY})$. 
Table 2. Safety stresses of materials.

\begin{tabular}{lrrr}
\hline Materials & \multicolumn{3}{c}{ Material properties } \\
\cline { 2 - 4 } & Pressure safety stresses (MPa) & Tension safety stresses (MPa) & Shear safety stresses (MPa) \\
\hline Brick & 2.40 & 0.360 & 1.05 \\
Stone wall & 0.90 & 0.135 & 0.53 \\
Arches & 0.90 & 0.135 & 0.53 \\
\hline
\end{tabular}

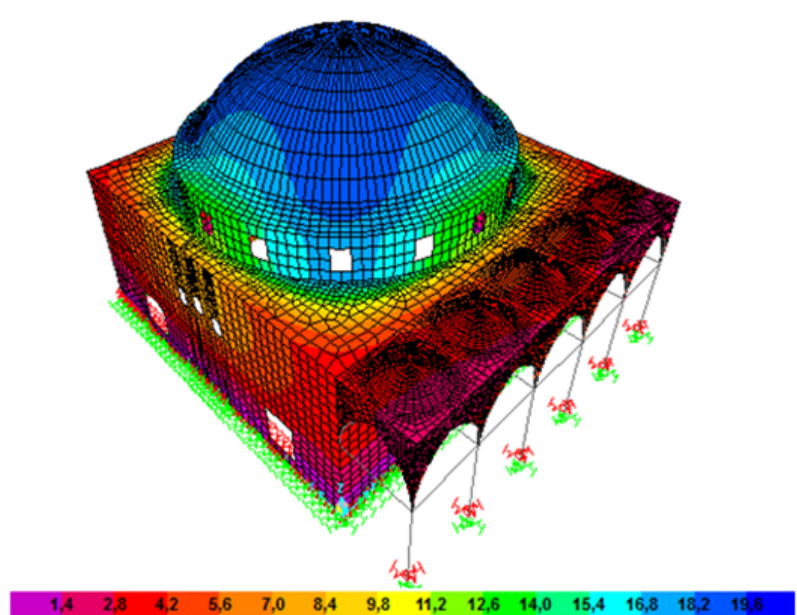

Figure 13. Maximum displacements contour diagram of the mosque with 16 window openings under dead load and earthquake load in the $z$ direction $(\mathrm{G}+\mathrm{EZ})$.

first and second seismic zones and $1.0 \mathrm{~m}$ for the third and fourth seismic zones.

- The plan length of the solid masonry wall which is between window and door openings shall not be less than $1.0 \mathrm{~m}$ for the first and second seismic zones and $0.8 \mathrm{~m}$ for the third and fourth seismic zones.

- Except for the corners of buildings, the plan length of a solid masonry wall which is between the intersection of the walls and the nearest window or door opening to the intersection of the orthogonal walls shall not be less than $0.50 \mathrm{~m}$ in all seismic zones.

- The plan length of each window or door opening shall not be more than $3.0 \mathrm{~m}$.

\subsection{Structural analyses of the mosque with 16 window openings}

The mosque had 16 window openings before the restoration, so the finite element model of the mosque was designed with 16 window openings. The model of the mosque has 27297 nodes, 127 frame elements, 25653 area elements and 1024603 3-D solid elements. The finite element model of the mosque with 16 window openings is shown in Fig. 3.

\subsubsection{Dynamic characteristics}

Dynamic characteristics were obtained with modal analysis. A $5 \%$ damping ratio was used in the analysis. A total of 20 mode shapes was obtained after the analyses. The first four mode shapes and frequencies are given in Fig. 4.

\subsubsection{Structural response of the mosque with 16 window openings under dead load and horizontal earthquake load $(\mathbf{G}+\mathbf{E X})$}

The maximum displacements contour diagram of the Hüsrev Pasha Mosque with 16 window openings under dead load and earthquake load $(\mathrm{G}+\mathrm{EX})$ is shown in Fig. 5. It can be seen in Fig. 5 that the maximum displacement occurred at the middle point of the big dome and had a value of $42.0 \mathrm{~mm}$. In addition, these displacements have a decreasing trend from the top of the dome to the lower part of the mosque.

The maximum tensile stresses contour diagram is shown in Fig. 6. It is seen in Fig. 6 that the maximum values of the tensile stresses for the outer surface of the mosque occurred at the side and in the lower part of the big dome, near the window spaces and transition areas between the side walls, and measured $1.05 \mathrm{MPa}$. The maximum tensile stresses for the inner surface of the mosque had a value of $1.00 \mathrm{MPa}$.

The maximum compression stresses contour diagram for the outer and inner surfaces of the Hüsrev Pasha Mosque with 16 window openings under dead load and earthquake load $(\mathrm{G}+\mathrm{EX})$ is shown in Fig. 7. It is seen in Fig. 7 that the maximum values of the compression stresses for the outer surface of the mosque occurred between the dome and the side wall transition areas, near window spaces on the dome, and measured 2.05 MPa. Additionally, these maximum compression stresses for the inner surface of the mosque had a value of $1.85 \mathrm{MPa}$.

The maximum shear stresses contour diagram for the outer and inner surfaces of the Hüsrev Pasha Mosque under dead load and earthquake load (G+EX) is shown in Fig. 8. It is seen in Fig. 8 that the maximum values of the shear stresses for the outer and inner surfaces of the mosque are 0.65 and $0.60 \mathrm{MPa}$ respectively. 


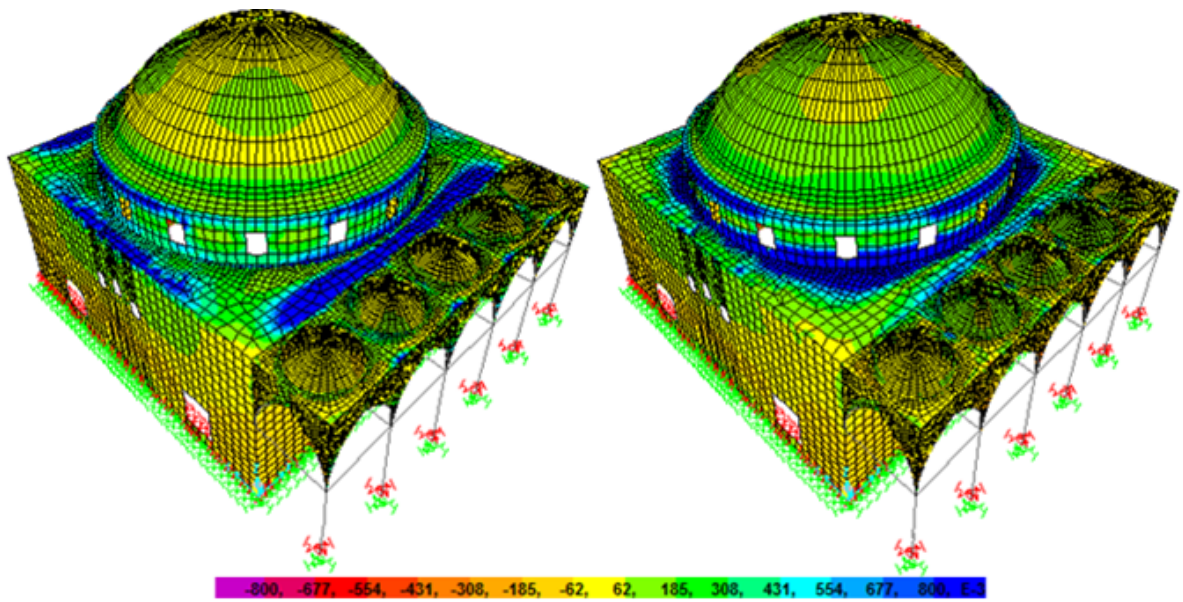

Figure 14. Maximum tensile stresses contour diagram for the outer and inner surfaces of the mosque with 16 window openings under dead load and earthquake load $(\mathrm{G}+\mathrm{EZ})$.

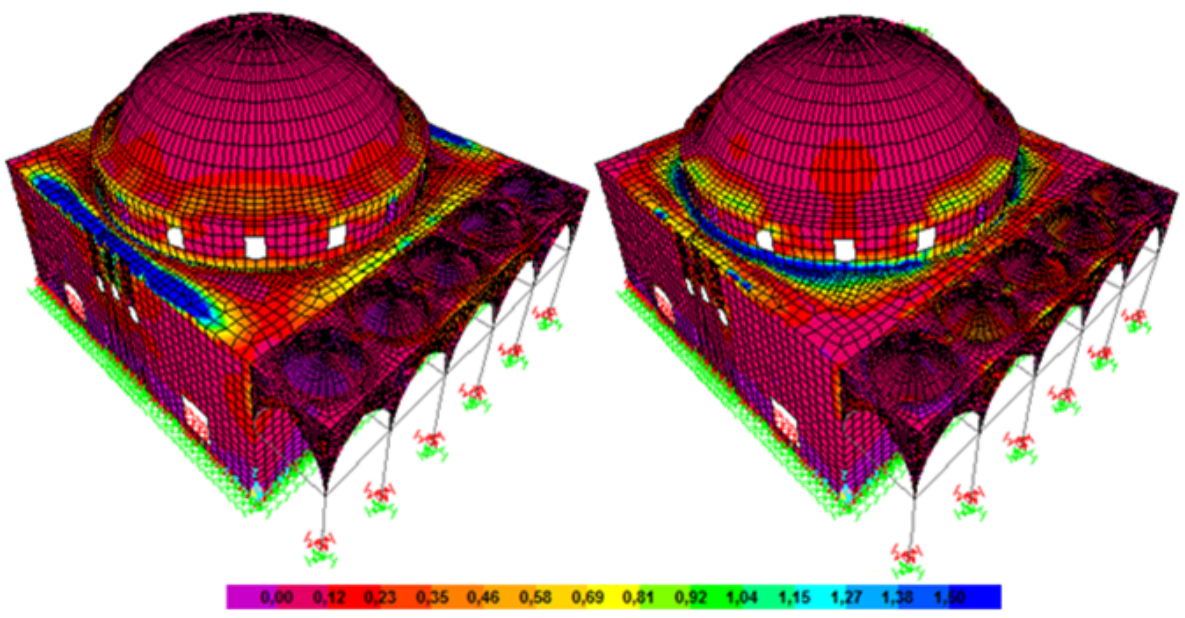

Figure 15. Maximum compression stresses contour diagram for the outer and inner surfaces of the mosque with 16 window openings under dead load and earthquake load (G+EZ).

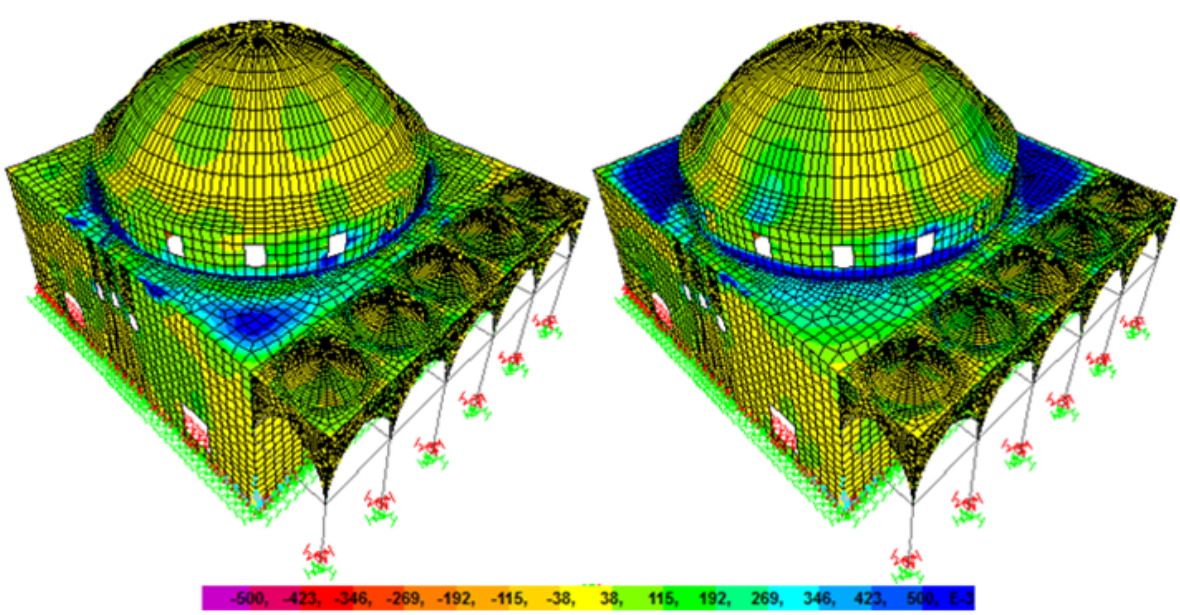

Figure 16. Maximum shear stresses contour diagram for the outer and inner surfaces of the mosque with 16 window openings under dead load and earthquake load (G+EZ). 


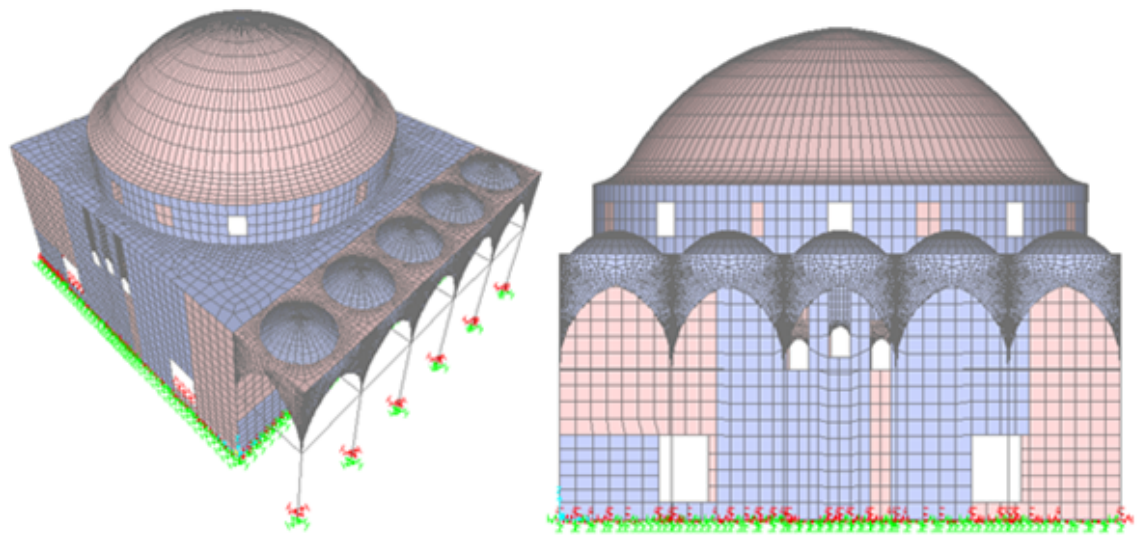

Figure 17. Finite element model of the mosque with eight window openings.

Table 3. Complete analysis results of the mosque with 16 and 8 window openings.

\begin{tabular}{|c|c|c|c|c|c|c|c|c|}
\hline \multicolumn{3}{|c|}{ Analysis data } & \multicolumn{6}{|c|}{ Analyses } \\
\hline & & & \multicolumn{2}{|c|}{$\begin{array}{l}\text { Dead and earthquake loads } \\
\text { ( } x \text { direction) }\end{array}$} & \multicolumn{2}{|c|}{$\begin{array}{l}\text { Dead and earthquake loads } \\
\text { ( } y \text { direction) }\end{array}$} & \multicolumn{2}{|c|}{$\begin{array}{l}\text { Dead and earthquake loads } \\
\text { ( } z \text { direction) }\end{array}$} \\
\hline & & & 16 window & 8 window & 16 window & 8 window & 16 window & 8 window \\
\hline \multicolumn{3}{|c|}{ Displacement (mm) } & 42.0 & 36.0 & 44.0 & 39.0 & 19.6 & 9.80 \\
\hline \multirow{6}{*}{ Stresses (MPa) } & Compression & Outer & 2.05 & 1.74 & 1.15 & 1.00 & 1.35 & 1.15 \\
\hline & & Inner & 1.85 & 1.51 & 1.10 & 0.95 & 1.25 & 1.05 \\
\hline & Tension & Outer & 1.05 & 0.95 & 0.95 & 0.80 & 0.85 & 0.69 \\
\hline & & Inner & 1.00 & 0.90 & 0.75 & 0.65 & 0.80 & 0.58 \\
\hline & Shear & Outer & 0.65 & 0.55 & 0.60 & 0.50 & 0.50 & 0.30 \\
\hline & & Inner & 0.60 & 0.50 & 0.55 & 0.45 & 0.45 & 0.20 \\
\hline
\end{tabular}

\subsubsection{Structural response of the mosque with 16 window openings under dead load and horizontal earthquake load $(\mathrm{G}+\mathrm{EY})$}

The maximum displacements contour diagram of the Hüsrev Pasha Mosque with 16 window openings under dead load and earthquake load $(\mathrm{G}+\mathrm{EY})$ is shown in Fig. 9. It can be seen in Fig. 9 that the maximum displacement occurred at the middle point of the big dome and had a value of $44.0 \mathrm{~mm}$. In addition, these displacements have a decreasing trend from the top of the dome to the lower part of the mosque.

The maximum tensile stresses contour diagram is shown in Fig. 10. It is seen in Fig. 10 that the maximum values of the tensile stresses for the outer surface of the mosque occurred at the side and in the lower part of the big dome, near the window spaces and transition areas between the side walls, and measured $0.95 \mathrm{MPa}$. The maximum tensile stresses for the inner surface of the mosque had a value of $0.75 \mathrm{MPa}$.

The maximum compression stresses contour diagram is shown in Fig. 11. It is seen in Fig. 11 that the maximum values of the compression stresses for the outer surface of the mosque occurred between the dome and the side wall transition areas, near window spaces on the dome, and measured 1.15 MPa. Additionally, these maximum compression stresses for the inner surface of the mosque had a value of $1.10 \mathrm{MPa}$.

The maximum shear stresses contour diagram for the outer and inner surfaces of the Hüsrev Pasha Mosque under dead load and earthquake load $(\mathrm{G}+\mathrm{EY})$ is shown in Fig. 12. It is seen in Fig. 12 that the maximum values of the shear stresses for the outer and inner surfaces of the mosque are 0.60 and $0.55 \mathrm{MPa}$ respectively.

\subsubsection{Structural response of the mosque with 16 window openings under dead load and horizontal earthquake load $(\mathbf{G}+\mathbf{E Z})$}

The maximum displacements contour diagram of the Hüsrev Pasha Mosque with 16 window openings under dead load and earthquake load $(\mathrm{G}+\mathrm{EZ})$ is shown in Fig. 13. It can be seen in Fig. 13 that the maximum displacement occurred at the middle point of the big dome and had a value of $19.6 \mathrm{~mm}$. In addition, these displacements have a decreasing trend from the top of the dome to the lower part of the mosque.

The maximum tensile stresses contour diagram is shown in Fig. 14. It is seen in Fig. 14 that the maximum values of the tensile stresses for the outer surface of the mosque occurred at the side and in the lower part of the big dome, near the window spaces and transition areas between the side walls, 
and measured $0.85 \mathrm{MPa}$. The maximum tensile stresses for the inner surface of the mosque had a value of $0.80 \mathrm{MPa}$.

The maximum compression stresses contour diagram is shown in Fig. 15. It is seen in Fig. 15 that the maximum values of the compression stresses for the outer surface of the mosque occurred between the dome and side wall transition areas, near window spaces on the dome, and measured 1.35 MPa. Additionally, these maximum compression stresses for the inner surface of the mosque had a value of 1.25 MPa.

The maximum shear stresses contour diagram for the outer and inner surfaces of the Hüsrev Pasha Mosque under dead load and earthquake load (G+EZ) is shown in Fig. 16. It is seen in Fig. 16 that the maximum values of the shear stresses for the outer and inner surfaces of the mosque are 0.50 and $0.45 \mathrm{MPa}$ respectively.

\subsection{Structural analyses of the mosque with eight window openings}

The mosque had eight window openings before the restoration, so the finite element model of the mosque was designed with eight window openings. The finite element model of the mosque with eight window openings is shown in Fig. 17. Using the modal analysis, the first four natural frequencies were obtained, with values of $3.81,3.87,4.81$ and $5.78 \mathrm{~Hz}$ respectively. Mode shapes were obtained as translation in the $x$ direction, translation in the $y$ direction, squeeze and torsion respectively. Results of earthquake analyses are given in Table 3.

\section{Conclusions}

In this study the restoration effect on the earthquake behavior of masonry mosques is investigated considering different opening ratios on the dome. As a result of the study, the following observations were made:

- Reductions of window openings caused an increase in the frequencies. This situation shows that the reduction of window openings affects the structural performance and stability of the mosque positively.

- When the stress results are examined, it is seen that the compression and shear stresses values do not exceed the recommended compression and shear stresses values for masonry structures in the Turkish Earthquake Code (2007).

- Tension stresses occurred near the openings, bottom of walls and under the dome areas locally for each case.

- Compression stresses, tension stresses and shear stresses collect on some critical areas, especially near openings and crossing points; because of this, those areas must be monolithically rebuilt in the restoration process. Fibre-reinforced polymer composite strengthening can be used to resist the tension stresses in restoration applications.

- According to the results, the displacement, compression, tension and shear stresses decrease when the openings are reduced.

Consequently, the reduction of window openings ensures the integrity of the walls, so this situation supports the structural performance of the mosque. It is seen from the study that restoration applications, especially reduction of the window openings on the dome, improve the earthquake response of the mosque.

Data availability. The data are not publically available.

Competing interests. The authors declare that they have no conflict of interest.

Special issue statement. This article is part of the special issue "Damage of natural hazards: assessment and mitigation". It is not associated with a conference.

Edited by: Thomas Glade

Reviewed by: Barış Sevim and one anonymous referee

\section{References}

Altunisik, A. C., Kanbur, B., and Genc, A. F.: The effect of arch geometry on the structural behavior of masonry bridges, Smart Struct. Syst., 16, 1069-1089, 2015.

Betti, M., Orlando, M., and Vignoli, A.: Static behaviour of an Italian medieval castle: damage assessment by numerical modeling, Comput. Struct., 89, 1956-1970, https://doi.org/10.1016/j.compstruc.2011.05.022, 2011.

Brandonisio, G., Lucibello, G., Mele, E., and De Luca, A.: Damage and performance evaluation of masonry churches in the 2009 L'Aquila earthquake, Eng. Fail. Anal., 34, 693-714, 2013.

Chen, X. and Liu, Y.: Numerical study of in-plane behaviour and strength of concrete masonry infills with openings, Eng. Struct., 82, 226-235, 2015.

Chisari, C., Macorini, L., Amadio, C., and Izzuddin, B. A.: An inverse analysis procedure for material parameter identification of mortar joints in unreinforced masonry, Comput. Struct., 155, 97105,2015

Lin, T. J. and LaFave, J. M.: Experimental structural behavior of wall-diaphragm connections for older masonry buildings, Constr. Build. Mater., 26, 180-189, 2012.

Milani, G. and Lourenço, P. B.: 3-D non-linear behavior of masonry arch bridges, Comput. Struct., 110, 133-150, 2012.

Minghini, F., Milani, G., and Tralli, A.: Seismic risk assessment of a $50 \mathrm{~m}$ high masonry chimney using advanced analysis techniques, Eng. Struct., 69, 255-270, 2014. 
Parisi, F., Lignola, G. P., Augenti, N., Prota, A., and Manfredi, G.: Rocking response assessment of in-plane laterally-loaded masonry walls with openings, Eng. Struct., 56, 1234-1248, 2013.

Peña, F., Lourenço, P. B., Mendes, N., and Oliveira, D. V.: Numerical models for the seismic assessment of an old masonry tower, Eng. Struct., 32, 1466-1478, 2010.

Salmanpour, A. H., Mojsilovic, N., and Schwartz, J.: Displacement capacity of contemporary unreinforced masonry walls: an experimental study, Eng. Struct., 89, 1-16, 2015.

SAP2000, Computers and Structures Inc. Berkeley, California, USA, 2015.

Seker, B. S., Cakir, F., Dogangun, A., and Uysal, H.: Investigation of the structural performance of a masonry domed mosque by experimental tests and numerical analysis, Earthq. Struct., 6, 335350,2014
Shariq, M., Abbas, H., Irtaza, H., and Qamaruddin, M.: Influence of openings on seismic performance of masonry building walls, Build. Environ., 43, 1232-1240, 2008.

TEC: Specification for Buildings to be Built in Seismic Zones, Ministry of Public Works and Settlement, General Directorate of Disaster Affairs, Earthquake Research Department, Ankara, Turkey, 2007.

Tiberti, S., Acito, M., and Milani, G.: Comprehensive FE numerical insight into Finale Emilia Castle behavior under 2012 Emilia Romagna seismic sequence: damage causes and seismic vulnerability mitigation hypothesis, Eng. Struct., 117, 397-421, 2016. 